\title{
NOTE
}

\section{Contamination introduced during rock sample powdering: Effects from different mill materials on trace element contamination}

\author{
ASAKO TAKAMASA* and SHUN'ICHI NAKAI \\ Earthquake Research Institute, The University of Tokyo, Tokyo 113-0032, Japan \\ (Received September 4, 2008; Accepted April 10, 2009)
}

\begin{abstract}
We examined blanks during powdering processes for thirty-three trace elements using ICP-MS (inductively coupled plasma mass spectrometry). Quartz sand was used as target of powdering with grinding mills of several kinds: an agate hand mill, agate ball mill, Fe hand mill, alumina ceramic hand mill and artificial crystalline quartz hand mill.

The results show that the artificial crystalline quartz hand mill is the purest grinder among the analyzed ones. This grinder is suitable for soft rock samples such as limestone. The alumina ceramic hand mill can reduce contamination, except for $\mathrm{Cs}, \mathrm{W}$ and $\mathrm{Pb}$. The agate hand mill and the agate ball mill introduce contamination whose level is depending on the individual device due to heterogeneity of the natural agate. The Fe hand mill introduces contamination of some siderophile elements such as Mo and W. The results of this study emphasize careful choice of a grinding mill for sample pulverizing.
\end{abstract}

Keywords: grinding mill, contamination, trace element, ICP-MS

\section{INTRODUCTION}

Sample preparation of rocks, prior to wet chemical analysis, includes crushing, splitting, and powdering (Potts, 2003). These processes homogenize rock samples and facilitate subsequent decomposition. During powdering, cross sample contamination and contamination from grinding facilities can occur. Although the former is avoidable by removing contaminants on the grinding facility by repeated pulverizing and washout by the sample to be analyzed, the later is unavoidable. For the sake of effective use of the high sensitivity analytical instruments such as ICP-MS, contamination caused by the grinding facilities during pulverization must be kept in an acceptably low level.

Several reports have described the influence of contamination from grinding facilities (Myers and Barnett, 1953; Barnett et al., 1955; Thompson and Bankston, 1970; Ando, 1986; Hickson and Juras, 1986; Iwansson and Landström, 2000). The results of those studies emphasize the importance of an appropriate choice of the grinding facility for the elements of interest. Using DC arc excitation and a photoelectric spectrometer, Thompson and Bankston (1970) examined contamination with twelve elements introduced during powdering and sieving. Their

*Corresponding author (e-mail: takamasa@eri.u-tokyo.ac.jp)

Copyright $@ 2009$ by The Geochemical Society of Japan. study showed that tungsten carbide vial, alumina mortar, and alumina-ceramic vial introduced contamination with several elements. They reported that boron carbide mortar, agate mortar, and leucite grinding vial did not introduce serious contamination, except for boron contamination engendered by the boron carbide mortar. Hickson and Juras (1986) examined contamination resulting from the use of (1) high-carbon steel grinding plate, (2) chromesteel shatter box, (3) tungsten carbide shatter box, (4) agate mortar, and (5) corundum-ceramic hand mill using $\mathrm{X}$-ray fluorescence spectrometry and flameless atomic absorption spectrometry. They reported that the agate mortar produced no measurable contamination. Ando (1986) also recommended agate mortar for sample powdering. Iwansson and Landström (2000) examined contamination during powdering of rocks of several types in steel and cemented carbide grinding mills employing instrumental neutron activation analysis and inductively coupled plasma emission spectrometry. Their results showed that the degree of contamination is related to the amount of quartz crystal in a rock sample and the powdering time.

During the last two decades, the development of analytical instruments has enabled determination of ultratrace element concentration at ppb or ppt levels in rocks. As the result of the development, some ultra trace elements, such as platinum group elements, together with Mo and $\mathrm{W}$, have become important geochemical tracers. We have applied ICP-MS with higher sensitivity ( ppb 
Table 1. Trace element abundances in blank quartz sand and acid blank

\begin{tabular}{|c|c|c|c|c|c|c|}
\hline & $\begin{array}{l}\text { Blank quartz sand \#1 } \\
\quad(50.7 \mathrm{mg})^{*}\end{array}$ & $\begin{array}{l}\text { Blank quartz sand \#2 } \\
\quad(31.2 \mathrm{mg})^{*}\end{array}$ & $\begin{array}{l}\text { Blank quartz sand \#3 } \\
\quad(35.9 \mathrm{mg})^{*}\end{array}$ & Average & Acid Blank & $\begin{array}{l}\text { Blank corrected abundances } \\
\text { in quartz sand }\end{array}$ \\
\hline Co $(n g / g)$ & 1200 & 1200 & 1200 & 1200 & 8 & 1200 \\
\hline $\mathrm{Cu}$ & 200 & $<200$ & 500 & 350 & 1 & 350 \\
\hline $\mathrm{Zn}$ & 400 & 500 & 600 & 500 & 3 & 500 \\
\hline $\mathrm{Rb}$ & $<80$ & $<80$ & $<80$ & $<80$ & $<0.6$ & $<80$ \\
\hline $\mathrm{Sr}$ & 100 & 100 & 200 & 100 & $<0.4$ & 100 \\
\hline $\mathrm{Y}$ & $<2$ & $<2$ & 2 & 2 & $<0.01$ & $<2$ \\
\hline $\mathrm{Zr}$ & 100 & 100 & 100 & 100 & 1 & 99 \\
\hline $\mathrm{Nb}$ & 230 & 230 & 210 & 220 & 3 & 220 \\
\hline Mo & $<7$ & $<7$ & $<7$ & $<7$ & $<0.05$ & $<7$ \\
\hline $\mathrm{Ru}$ & $<8$ & $<8$ & $<8$ & $<8$ & $<0.06$ & $<8$ \\
\hline $\mathrm{Pd}$ & $<10$ & $<10$ & $<10$ & $<10$ & $<0.1$ & $<10$ \\
\hline $\mathrm{Ag}$ & 41 & 32 & 42 & 38 & 0.27 & 38 \\
\hline $\mathrm{Cs}$ & $<30$ & $<30$ & $<30$ & $<30$ & $<0.13$ & $<30$ \\
\hline $\mathrm{Ba}$ & 280 & 140 & 320 & 250 & $<0.14$ & 250 \\
\hline $\mathrm{La}$ & $<0.6$ & 1 & 2 & 2 & 0.005 & 2 \\
\hline $\mathrm{Ce}$ & $<1$ & 2 & 1 & 2 & 0.005 & 2 \\
\hline $\operatorname{Pr}$ & $<0.6$ & $<0.6$ & $<0.7$ & $<0.7$ & $<0.02$ & $<0.7$ \\
\hline $\mathrm{Nd}$ & $<3$ & $<3$ & $<3$ & $<3$ & $<0.001$ & $<3$ \\
\hline Sm & $<3$ & $<3$ & $<3$ & $<3$ & $<0.002$ & $<3$ \\
\hline $\mathrm{Gd}$ & $<1$ & $<1$ & $<1$ & $<1$ & $<0.003$ & $<1$ \\
\hline Dy & $<0.9$ & $<0.9$ & $<0.9$ & $<0.9$ & $<0.006$ & $<0.9$ \\
\hline $\mathrm{Er}$ & $<0.8$ & $<0.8$ & $<0.8$ & $<0.8$ & $<0.006$ & $<0.8$ \\
\hline $\mathrm{Tm}$ & $<0.3$ & $<0.3$ & $<0.3$ & $<0.3$ & $<0.002$ & $<0.3$ \\
\hline $\mathrm{Yb}$ & $<0.8$ & 2 & $<0.8$ & 2 & $<0.01$ & 2 \\
\hline $\mathrm{Lu}$ & $<0.3$ & $<0.3$ & $<0.3$ & $<0.3$ & $<0.006$ & $<0.3$ \\
\hline $\mathrm{Hf}$ & 5 & 5 & 6 & 5 & 0.08 & 5 \\
\hline $\mathrm{Ta}$ & 3 & 4 & 3 & 3 & 0.05 & 3 \\
\hline W & 29 & 32 & 31 & 31 & 0.2 & 31 \\
\hline $\mathrm{Ir}$ & 0.6 & $<0.5$ & $<0.5$ & 0.6 & $<0.006$ & 0.6 \\
\hline $\mathrm{Pt}$ & $<1$ & $<1$ & $<1$ & $<1$ & $<0.001$ & $<1$ \\
\hline $\mathrm{Pb}$ & 73 & 58 & 150 & 94 & $<0.06$ & 94 \\
\hline Th & $<0.6$ & $<0.6$ & $<0.6$ & $<0.6$ & $<0.003$ & $<0.6$ \\
\hline $\mathrm{U}$ & $<0.7$ & 1 & 1 & 1 & $<0.006$ & 1 \\
\hline
\end{tabular}

*Weight of quartz sand used for analysis.

detection level) than previous analytical apparatus to examine contamination with thirty-three elements from typical grinding mills and a new artificial crystal quartz mortar. We have presented the results and suggest appropriate choice of the grinding facilities.

\section{EXPERIMENT}

\section{Reagents and materials}

All chemical reagents (ultra pure grades) were used without further purification: hydrofluoric acid (18083-1B; Kanto Kagaku), perchloric acid (32059-1B; Kanto Kagaku) and nitric acid (28163-1B; Kanto Kagaku). In addition, de-ionized water $\left(18.3 \mathrm{M} \Omega \mathrm{cm}^{-1}\right)$ was obtained using a Millipore Milli-Q purification system (Millipore Corp.). Cleaned perfluoroalkoxy (PFA) vials (Savillex Corp.) were used throughout this study for decomposition and dilution. The vials have been cleaned in heated $\mathrm{HNO}_{3}, \mathrm{HCl}$, and then pure water baths. Finally, the in- sides of the vials were cleaned using UP-grade HF and EL-grade $\mathrm{HNO}_{3}$, and were rinsed in Milli-Q water before use.

\section{Powdering experiments}

To prevent contamination from the environment, powdering experiments were conducted in a class 10000 preclean room, except an agate planetary ball mill. We investigated contamination from the following grinding facilities in this study: an alumina ceramic hand mill, artificial crystalline quartz hand mill, Fe hand mill, agate hand mill, and all-agate planetary ball-mill.

In this study, quartz sand (172-00015; Wako Pure Chemical Industries, Ltd., natural crystal) used for powdering tests was analyzed without powdering in order to determine impurities in the quartz sand. That quartz sand in question was ultrasonically washed with Milli-Q for 30 minutes and dried and analyzed without powdering (sample digestion method will be explained in Subsec- 
tion "Trace element abundance analysis"). The results are shown as blank quartz sand in Table 1. That quartz sand was pulverized using the mills as described above. The respective influences of contamination from the mills were determined by subtracting the trace element abundances in the raw quartz sand from those in the pulverized quartz sand. Details of each powdering experiment are described in the following.

\section{Alumina ceramic hand mill}

Before using the alumina ceramic hand mill (Scientific Instruments and Utensil, ACE-2H-120), we cleaned it by an ultrasonic cleaner with Milli-Q water for 15 minutes for three times and crushing the quartz sand for three times for five minutes. Powdering time was about 10 minutes and grain size of the pulverized quartz sand was about 200 mesh.

\section{Artificial quartz hand mill}

The artificial crystalline quartz hand mill is a new vessel produced by Kido Agate Manufacture. The mill vessel material consists of $99.99 \%$ high-purity silica glass obtained by using an electric melting method. It was cleaned by an ultrasonic cleaner with Milli-Q water for 15 minutes for three times and then pulverizing the quartz sand twice for five minutes before powdering process. Powdering time was about 10 minutes and grain size of the pulverized quartz sand was about 200 mesh.

\section{Fe hand mill}

Fe hand mill (manual type, San'ei kako Co. Ltd.) was washed by Milli-Q water and ethanol (UGR grade, Kanto Kagaku) using Kimwipes (Kimberly-Clark). The mill was cleaned by 10 minute-pulverizing of the quartz sand for ten times. Then the quartz sand for blank analyses was crushed for 10 minutes. The grain size of the powdered quartz sand was about 200 mesh.

\section{Agate hand mill}

We cleaned an agate hand mill (manual type, Iuchi 6547-07) by an ultrasonic cleaner with Milli-Q water for 15 minutes for three times and then powdered the quartz sand for three times for five minutes before pulverizing. Powdering time was about 10 minutes and grain size of the pulverized quartz sand was about 200 mesh.

\section{Agate ball mill}

The agate ball mill (planetary-type rotating machine, Fritsch Pulverisette 5/4; Alfred Fritsch \& Co., Oberstein, F.R.G. Fritsch Japan Co., Ltd., Brazilian Agate) was cleaned by ultrasonic cleaner with Milli-Q water for 15 minutes for three times and then by crushing the quartz sand for five times (mill rotation speed at $300 \mathrm{rpm}$ for five minutes) before pulverizing the analyzed sample. The agate ball mill uses seven agate balls of $17 \mathrm{~mm}$ in diameter for sample crushing with mill rotation speed at 300 rpm for 15 minutes. The grain size of the powdered quartz sand was about 300 mesh. This automatic mill is installed in rock cutting room not in the pre-clean room. The surroundings of the machine were cleaned by Milli-Q water using Kimwipes.

Additionally, we measured the trace element concentration of an agate ball and an agate mill vessel. These agate materials were crushed with a hammer with being wrapped in a plastic bag and Kimwipes. The agate chips were then pulverized to powder using the agate ball mill after it had been cleaned ultrasonically with Milli-Q water for 30 minutes. To investigate possible heterogeneity of trace element abundances in agate mill material, a ball and two pieces of vessels were analyzed.

\section{Trace element abundance analyses}

In order to prevent contamination from the environment, chemical experiments were conducted in a class 5000 clean room.

About 30 40 mg of pulverized quartz sand samples were weighed into $7 \mathrm{ml}$ PFA vials. To them were added 25 drops $\mathrm{HF}$ and 8 drops $\mathrm{HClO}_{4}$. They were then digested on a heater at $120^{\circ} \mathrm{C}$ for $24 \mathrm{~h}$. The acids were dried at $120 \sim 190^{\circ} \mathrm{C}$. Then these residues were dissolved in $2 \%$ $\mathrm{HNO}_{3}$ with trace amounts of HF to increase the solubility of high field strength elements (HFSEs). Finally, they were diluted 2000 4000 times dependent on abundance of contaminant with internal standards of indium (In) and bismuth (Bi) (SPEX Industries Inc.).

The concentrations of trace elements were measured using ICP-MS with a quadrupole mass analyzer (PQ-3; Thermo Elemental, Winsford, UK) at the Earthquake Research Institute of the University of Tokyo. Trace element abundances were determined using sensitivity methods with matrix effect corrections made by using internal standards. The sample uptake rates were about $1 \mathrm{ml}$ $\min ^{-1}$. Between analyses, the nebulizer system was rinsed with $2 \% \mathrm{HNO}_{3}$ or $2 \% \mathrm{HNO}_{3}$ with trace $\mathrm{HF}$ for $10 \sim 15$ minutes to reduce the memory of background. The detection limit of ICP-MS analysis is defined by $3 \sigma$ of background counts measured while blank solution $\left(2 \% \mathrm{HNO}_{3}\right.$ with trace $\mathrm{HF}$ ) is nebulized. In the following tables, trace element abundance will be reported as "< detection limit" when measured signal of an element is smaller than the $3 \sigma$ of background counts for the element measured on the day of analysis. Standards were prepared by mixing standard solutions of XSTC-13 (containing thirty-one elements, such as $\mathrm{Co}, \mathrm{Cu}, \mathrm{Ag}$ and Th), XSTC-1(containing sixteen elements, such as rare earth elements, $\mathrm{Sr}, \mathrm{Zr}, \mathrm{Nb}$, Mo, Ru, Pd, Ag, Ba, Hf, Ta, W, Ir and Pt (SPEX Industries Inc.) diluted in a $2 \%$ of $\mathrm{HNO}_{3}$. Element concentrations in the standard solutions were 0.25 to $100 \mathrm{ppb}$. 
Table 2. Contamination introduced during powdering and trace element abundances in JB-2 used for normalization

\begin{tabular}{|c|c|c|c|c|c|c|c|}
\hline & $\begin{array}{c}\text { Alumina ceramic } \\
\text { hand mill } \\
(42.47 \mathrm{mg})^{*}\end{array}$ & $\begin{array}{c}\text { Artificial quartz } \\
\text { hand mill } \\
(53.09 \mathrm{mg})^{*}\end{array}$ & $\begin{array}{l}\text { Fe hand mill } \\
(67.03 \mathrm{mg})^{*}\end{array}$ & $\begin{array}{l}\text { Agate ball mill } \\
\text { using new balls } \\
(53.59 \mathrm{mg})^{*}\end{array}$ & $\begin{array}{l}\text { Agate ball mill } \\
\text { using used balls } \\
(49.95 \mathrm{mg})^{*}\end{array}$ & $\begin{array}{l}\text { Agate hand mill } \\
(58.51 \mathrm{mg})^{*}\end{array}$ & $\begin{array}{c}\text { JB-2 } \\
\text { (Imai } \text { et al., 1995) }\end{array}$ \\
\hline Co (ng/g) & 700 & 900 & 1800 & 200 & 200 & - & 38000 \\
\hline $\mathrm{Cu}$ & 300 & 300 & 12000 & $<400$ & $<400$ & - & 225000 \\
\hline $\mathrm{Zn}$ & 200 & 200 & 100 & 500 & 90 & - & 108000 \\
\hline $\mathrm{Rb}$ & 100 & $<9$ & $<80$ & $<80$ & 90 & 400 & 7370 \\
\hline $\mathrm{Sr}$ & 400 & $<40$ & 170 & 40 & 200 & 500 & 178000 \\
\hline Y & 3 & $<3$ & 5 & 20 & 20 & 20 & 24900 \\
\hline $\mathrm{Zr}$ & 100 & 58 & $<20$ & $<100$ & 52 & 50 & 51200 \\
\hline $\mathrm{Nb}$ & 40 & 58 & 100 & $<200$ & $<200$ & 11 & 1580 \\
\hline Mo & 15 & 8.0 & 690 & $<7$ & 25 & 21 & 1080 \\
\hline $\mathrm{Ru}$ & $<9$ & $<10$ & $<8$ & $<8$ & $<8$ & $<8$ & \\
\hline $\mathrm{Pd}$ & $<9$ & $<10$ & $<10$ & $<10$ & $<10$ & $<10$ & 6.3 \\
\hline $\mathrm{Ag}$ & $<9$ & $<10$ & 16 & 11 & 5 & $<5$ & 72 \\
\hline Cs & 41 & $<5$ & $<20$ & $<20$ & 43 & 100 & 850 \\
\hline $\mathrm{Ba}$ & 930 & $<20$ & 2500 & 87 & 310 & 1500 & 222000 \\
\hline $\mathrm{La}$ & 3.2 & $<1$ & 2.8 & 2.2 & 14 & 3.5 & 2350 \\
\hline $\mathrm{Ce}$ & 8.8 & $<1$ & 6.1 & 11 & 32 & 6.5 & 6760 \\
\hline $\operatorname{Pr}$ & $<1$ & $<1$ & 1.0 & $<0.7$ & 4.1 & $<1$ & 1010 \\
\hline $\mathrm{Nd}$ & 4.3 & $<6$ & 5.7 & $<3$ & 14 & $<2$ & 6630 \\
\hline Sm & $<8$ & $<10$ & 5.2 & $<3$ & $<3$ & $<3$ & 2310 \\
\hline $\mathrm{Gd}$ & $<2$ & $<3$ & $<2$ & $<1$ & 3.4 & $<2$ & 3280 \\
\hline Dy & $<3$ & $<4$ & $<1$ & 2.8 & 2.7 & $<2$ & 3730 \\
\hline $\mathrm{Er}$ & $<2$ & $<3$ & $<1$ & 0.9 & 1.3 & $<2$ & 2600 \\
\hline $\mathrm{Tm}$ & $<1$ & $<2$ & $<0.3$ & $<0.3$ & 0.5 & $<0.2$ & 410 \\
\hline $\mathrm{Yb}$ & $<4$ & $<5$ & $<1$ & 0.9 & 1.9 & $<1$ & 2620 \\
\hline $\mathrm{Lu}$ & $<1$ & $<2$ & 0.3 & $<0.3$ & 0.4 & $<0.3$ & 400 \\
\hline $\mathrm{Hf}$ & $<5$ & $<7$ & 0.5 & $<4$ & $<4$ & 13 & 1490 \\
\hline $\mathrm{Ta}$ & $<2$ & $<2$ & 5 & 0.5 & 0.4 & $<0.4$ & 130 \\
\hline W & 30 & 12 & 340 & 16 & 84 & 25 & 260 \\
\hline $\mathrm{Ir}$ & $<3$ & $<3$ & $<0.5$ & $<0.5$ & $<0.5$ & $<1$ & \\
\hline $\mathrm{Pt}$ & $<6$ & $<9$ & $<2$ & $<2$ & 2.5 & $<2$ & 4 \\
\hline $\mathrm{Pb}$ & 170 & 15 & $<7$ & 5.0 & 3.2 & 165 & 5360 \\
\hline Th & $<3$ & $<4$ & $<0.6$ & $<0.6$ & 7.3 & $<3$ & 350 \\
\hline $\mathrm{U}$ & $<3$ & $<4$ & 3 & 11 & 13 & 15 & 180 \\
\hline
\end{tabular}

*Weight of quartz sand powdered in analysis.

"Acid Blank" shown in Table 1 was measured as follows: the same amount of $\mathrm{HF}$ and $\mathrm{HClO}_{4}$ used for decomposition of quartz sand were added in an empty $7 \mathrm{ml}$ PFA vial. The vial was heated for the same elapsed time as the quartz digestion process on a hotplate, then, the acids were evaporated to dryness. Three drops of ultrapure-grade $\mathrm{HNO}_{3}$ and six drops of Milli-Q water were used to leach contamination in the vials and it was diluted to $30 \mathrm{ml}$ for ICP-MS analysis. No internal standard element was added to the solution.

\section{RESULTS AND DISCUSSIONS}

\section{Blank quartz sand}

Quartz sand used as sample for powdering tests was first analyzed without pulverization. The element concentrations in three splits of the quartz sand are presented as blank quartz sand (Blank quartz sand \#1 to \#3) in Table 1 along with acid blank concentration.

The results show that quartz sand contains high amounts of $\mathrm{Sr}, \mathrm{Zr}, \mathrm{Ag}, \mathrm{Ba}, \mathrm{W}$ and $\mathrm{Pb}$. This observed variation could have been caused by contamination from the environment. However, considering the acid blank was much lower compared with the abundances of the elements in the quartz sand without pulverization, the observed variation was probably caused from the sample heterogeneity.

\section{Alumina ceramic hand mill}

Thompson and Bankston (1970) reported that the alumina ceramic hand mill (SPEX Industries, Inc.) caused contamination of $\mathrm{Li}, \mathrm{B}, \mathrm{Al}, \mathrm{Ti}, \mathrm{Mn}, \mathrm{Fe}, \mathrm{Co}, \mathrm{Cu}, \mathrm{Zn}, \mathrm{Ga}$, $\mathrm{Zr}$ and $\mathrm{Ba}$. We used an alumina ceramic mill composed of $93 \% \mathrm{Al}_{2} \mathrm{O}_{3}$ and $5 \% \mathrm{SiO}_{2}$. In addition to these elements reported by Thompson and Bankston (1970), our results indicate that the alumina mill vessel can be the source of 


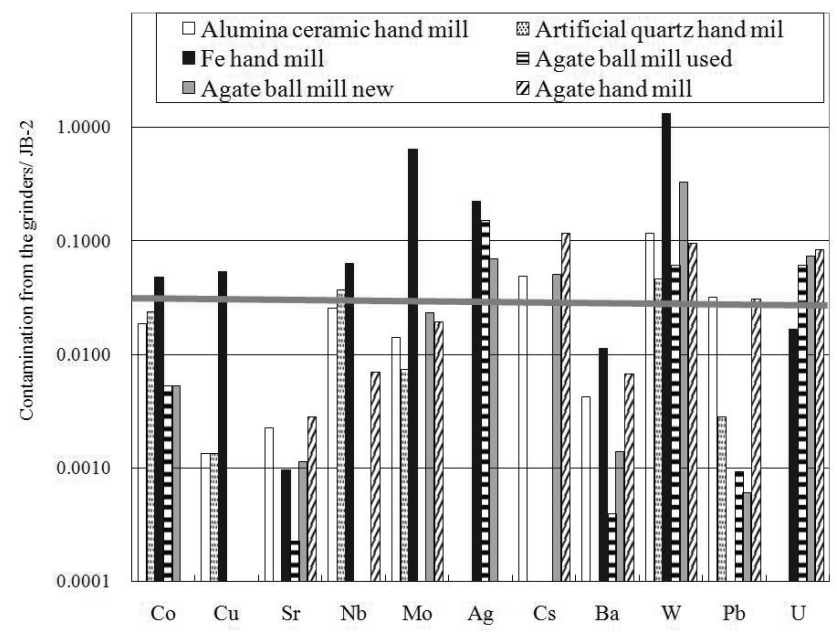

Fig. 1. JB-2 normalized abundances of contaminations introduced during powdering with several grinders. Trace element abundances in JB-2 used for normalization in this plot are from Imai et al. (1995) (Table 2). No bar is shown for a case when the influence of contamination is below 0.0001. Horizontal solid line in the figure shows where the influence of contamination from powdering process is $5 \%$.

the contamination for $\mathrm{Rb}, \mathrm{Sr}, \mathrm{Mo}, \mathrm{Cs}, \mathrm{Ba}$ and $\mathrm{Pb}$ (Table 2). We think that the level of contaminants will be critical in preparation of meteorite samples and some terrestrial rocks depleted in these elements. Figure 1 shows a multi-element pattern for contamination during powdering normalized to a terrestrial basalt sample (a standard rock of JB-2 distributed from Geological Survey of Japan). JB-2 is used for normalization because it has a trace element abundance pattern typical of subduction-related basalt and is not enriched in incompatible elements. The figure shows that the $\mathrm{Cs}$ and $\mathrm{W}$ contaminations from the mill are $11 \%$ and $5 \%$, respectively, compared to one gram of JB-2.

\section{Artificial crystalline quartz hand mill}

This hand mill contains the least amount of contaminants compared with other mills in this study, except for $\mathrm{Co}, \mathrm{Nb}$ and $\mathrm{Pb}$ (Fig. 1). It is useful for soft rock samples, such as sediment with the Mohs scale of mineral hardness level below 6 , although it is inadequate for crushing hard rock such as basalt. Figure 1 shows that $\mathrm{Sr}, \mathrm{Cs}, \mathrm{Ba}$ and $\mathrm{U}$ contaminations from this grinding mill are lower than those from other mills.

\section{Fe hand mill}

An Fe hand mill and an Fe hammer are widely used for initial splitting of a rock block into small fragments before powdering with agate, alumina ceramic, or tungsten carbide mill. However, an Fe hand mill is expected
Table 3. Trace element abundances in agate material

\begin{tabular}{|c|c|c|c|}
\hline & $\begin{array}{l}\text { Agate ball } \\
(31.13 \mathrm{mg})^{*}\end{array}$ & $\begin{array}{l}\text { Agate mill \#1 } \\
(39.41 \mathrm{mg})^{*}\end{array}$ & $\begin{array}{l}\text { Agate mill \#2 } \\
(37.35 \mathrm{mg})^{*}\end{array}$ \\
\hline Co (ng/g) & 1000 & 1000 & 1000 \\
\hline $\mathrm{Cu}$ & $<200$ & 2000 & 1000 \\
\hline $\mathrm{Zn}$ & 4000 & 1000 & 2000 \\
\hline $\mathrm{Rb}$ & 400 & 300 & 300 \\
\hline $\mathrm{Sr}$ & 1000 & 1000 & 600 \\
\hline $\mathrm{Y}$ & 2000 & 1000 & 900 \\
\hline $\mathrm{Zr}$ & 94 & 220 & 110 \\
\hline $\mathrm{Nb}$ & 200 & 190 & 160 \\
\hline Mo & $<7$ & $<7$ & $<7$ \\
\hline $\mathrm{Ru}$ & $<7$ & $<7$ & $<7$ \\
\hline $\mathrm{Pd}$ & $<20$ & $<20$ & $<20$ \\
\hline $\mathrm{Ag}$ & 46 & 22 & 31 \\
\hline Cs & $<30$ & $<30$ & $<30$ \\
\hline $\mathrm{Ba}$ & 730 & 950 & 540 \\
\hline $\mathrm{La}$ & 22 & 24 & 11 \\
\hline $\mathrm{Ce}$ & 67 & 95 & 84 \\
\hline $\operatorname{Pr}$ & 8 & 6 & 3 \\
\hline $\mathrm{Nd}$ & 30 & 22 & 11 \\
\hline $\mathrm{Sm}$ & 13 & 9 & 5 \\
\hline $\mathrm{Gd}$ & 32 & 18 & 13 \\
\hline Dy & 110 & 79 & 66 \\
\hline Er & 130 & 110 & 96 \\
\hline $\mathrm{Tm}$ & 19 & 24 & 21 \\
\hline $\mathrm{Yb}$ & 99 & 170 & 150 \\
\hline $\mathrm{Lu}$ & 12 & 23 & 21 \\
\hline $\mathrm{Hf}$ & 4 & 8 & $<4$ \\
\hline $\mathrm{Ta}$ & 3 & 3 & 3 \\
\hline W & 26 & 31 & 22 \\
\hline Ir & $<0.5$ & $<0.5$ & $<0.5$ \\
\hline $\mathrm{Pt}$ & $<2$ & $<2$ & $<2$ \\
\hline $\mathrm{Pb}$ & 130 & 800 & 380 \\
\hline Th & $<0.6$ & 3 & 1 \\
\hline $\mathrm{U}$ & 88 & 420 & 400 \\
\hline
\end{tabular}

*Weight of agate material used for analysis.

to contain siderophile elements such as $\mathrm{Co}, \mathrm{Ni}$ and Mo. Although an Fe mill is not usually used for fine pulverizing in many cases, we investigated contamination from an Fe mill with the same powder preparation procedure used for other vessel.

The Fe hand mill used in this study introduced contamination with $\mathrm{Co}$, as expected. We also observed high abundances of Mo, Ag, and W. Lithophilic elements $\mathrm{Nb}$ and $\mathrm{Ba}$, were also detected. Because Fe metal is ductile, the mill material might easily stick to the rock chips. Appropriate care should be taken when crushing hard rocks such as kimberlites and high-pressure metamorphic rocks.

Figure 1 shows that the contamination introduced by this grinding mill is relatively higher compared with other grinding facilities. $\mathrm{Nb}, \mathrm{Mo}, \mathrm{Ag}$ and $\mathrm{W}$ contaminations during pulverization are 130,64, 22 and $6 \%$, respectively, of those elements from the sample of JB-2 when one gram of JB-2 is powdered. 
Agate hand mill and Agate ball mill

Table 2 compares the contaminations introduced by an agate ball mill with those by the agate hand mill. The table shows that $\mathrm{Rb}, \mathrm{Sr}, \mathrm{Cs}, \mathrm{Ba}$, and $\mathrm{Pb}$ were contaminated during powdering with an agate hand mill. We compared contamination introduced by pulverization of quartz sand with new and previously used agate balls with the same vessel (Table 2) and also measured the chip of the agate mill vessel and the agate ball (Alfred Fritsch \& Co., Oberstein, F.R.G. Fritsch Japan Co., Ltd., Brazilian Agate) (Table 3 ).

Thompson and Bankston (1970), Hickson and Juras (1986), and Ando (1986) recommended agate mortar for powdering silicate rock samples. However, our results showed that the agate hand mill and agate ball mill can be a source of contamination for $\mathrm{Ag}, \mathrm{Cs}, \mathrm{W}$ and $\mathrm{U}$ (Fig. 1). It appears that powdering with an agate hand mill caused more contamination of $\mathrm{Sr}$ and $\mathrm{Cs}$ than pulverizing with a ball mill (Fig. 1). Furthermore Fig. 1 suggests that the contamination from the used agate ball was not larger than that from the new one. For example, when one gram of JB-2 is powdered, Ag contamination from the new one is $15 \%$ but that from the old one is only $7 \%$ of Ag from the JB-2. Table 3 also suggests that trace element abundances, such as $\mathrm{Sr}, \mathrm{Ag}, \mathrm{Ba}, \mathrm{W}, \mathrm{Pb}$ and $\mathrm{U}$, in agate materials may be heterogeneous. Götze et al. (2001) reported wide variation in trace element abundances in agates from a single locality and from localities around the world. Our results may reflect difference in the origins of the agates. Therefore, contamination from agate hand mills with different conditions or vessels are certainly a complicated issue. It is recommended that contamination from each agate mill should be evaluated when it is used for powdering samples with low trace element abundances like Ag.

\section{Concluding remarks}

We compared contamination introduced during pulverization with grinding facilities of four kinds. The analyzed elements includes those with low abundances at ppb levels. An artificial crystalline quartz hand mill is the best tool with respect to limited contamination. This kind of mortar is the best for powdering soft rock sample like limestone except for a few elements such as $\mathrm{Pb}$. An alumina ceramic hand mill is sufficiently pure for pulverizing, most geological samples; however, it can be the sources of contamination for Cs and W. An Fe hand mill can be the source of large contamination for various elements $(\mathrm{Co}, \mathrm{Cu}, \mathrm{Nb}, \mathrm{Mo}, \mathrm{Ag}$, and $\mathrm{W})$. An agate hand mill and agate ball mill are considerably pure, but they can be the sources of contamination of $\mathrm{Ag}, \mathrm{Cs}, \mathrm{W}$ and $\mathrm{U}$. In addition, the agate material shows large heterogeneity in some trace elements such as $\mathrm{Sr}, \mathrm{Ba}$ and $\mathrm{U}$, among individual materials.

Our results indicate that the examination of contamination from a grinding mill is pre-requisite. One must carefully choose a mill according to the target elements to be analyzed, particularly elements at ppt or ppb levels in a sample. For example, the influence of the contamination from a grinding facility on trace elements such as $\mathrm{Mo}, \mathrm{Ag}$ and $\mathrm{W}$ is so serious that the grinding mill that can be used is limited. Extreme care is required in the pulverizing samples with lower trace element abundances such as mid-ocean ridge basalt. The influences of trace element contamination, such as $\mathrm{Cs}, \mathrm{Pb}$ and $\mathrm{Ba}$, can easily exceed $10 \%$ of those elements from MORB sample itself.

Acknowledgments-This research was partly supported by Grants-in-Aid for scientific research to SN from the Ministry of Education, Culture, Sports, Science and Technology. This work was also supported by a grant-in-aid for JSPS Research Fellowships for Young Scientists to AS. We are grateful to K. Kato for assistance with laboratory maintenance. We wish to thank Dr. T. Hiraga, who encouraged this study. Discussions with Drs. A. Yasuda, Y. Miura, Y. Orihasi, and K. Mibe are acknowledged.

\section{REFERENCES}

Ando, A. (1986) Preparation method of rock samples. Bulletin of the Geological Survey of Japan 37, 347-348 (in Japanese).

Barnett, P. R., Huleatt, W. P., Rader, L. F. and Myers, A. T. (1955) Spectrographic determination of contamination of rock samples after grinding with alumina ceramic. Amer. Jour. Sci. 253, 121-124.

Götze, J., Tichomirowa, M., Fuchs, H., Pilot, J. and Sharp, Z. D. (2001) Geochemistry of agars: a trace element and stable isotope study. Chem. Geol. 175, 523-541.

Hickson, C. J. and Juras, S. J. (1986) Sample contamination by grinding. Canad. Mineral. 24, 585-589.

Imai, N., Terashima, S., Itoh, S. and Ando, A. (1995) Compilation of analytical data for minor and trace elements in seventeen GSJ geochemical reference samples, "igneous rock series". Geostand. Newsl. 19(2), 135-213.

Iwansson, J. K. and Landström, O. (2000) Contamination of rock samples by laboratory grinding mills. Jour. Radioanal. Nucl. Chem. 244, 609-614.

Myers, A. T. and Barnett, P. R. (1953) Contamination of rock samples during grinding as determined spectrographically. Amer. Jour. Sci. 251, 814-830.

Potts, P. J. (2003) Concepts in analytical chemistry. Handbook of Rock Analysis, 1-46, Viridian Publishing.

Thompson, G. and Bankston, D. C. (1970) Sample contamination from grinding and sieving determined by emission spectrometry. Appl. Spectrosc. 24 210-219. 